\title{
A qualitative study examining health literacy and chronic illness self-management in Hispanic and non-Hispanic older adults
}

This article was published in the following Dove Press journal:

Journal of Multidisciplinary Healthcare

20 April 2017

Number of times this article has been viewed

\author{
Robin J Jacobs' \\ Raymond L Ownby ${ }^{2}$ \\ Amarilis Acevedo ${ }^{3}$ \\ Drenna Waldrop-Valverde ${ }^{4}$ \\ 'Department of Family and \\ Community Medicine, Baylor College \\ of Medicine, Houston, TX, ${ }^{2}$ College \\ of Osteopathic Medicine, ${ }^{3}$ College \\ of Psychology, Nova Southeastern \\ University, Fort Lauderdale, FL, ${ }^{4}$ Nell \\ Hodgson Woodruff School of Nursing, \\ Emory University, Atlanta, GA, USA
}

Correspondence: Robin J Jacobs

Department of Family and Community

Medicine, Baylor College of Medicine,

370I Kirby Drive, Suite 600, MS:

BCM700, Houston, TX 77098, USA

$\mathrm{Tel}+\mathrm{I} 7 \mid 37981090$

Fax + I 832787 I307

Email rjjacobs@bcm.edu
Purpose: Chronic illness and low levels of health literacy affect health outcomes for many individuals, particularly older adults and racial/ethnic minorities. This study sought to understand the knowledge, strengths, and areas of need regarding self-management of chronic illness in order to lay the groundwork for content development of an intervention to increase health literacy and maximize patient engagement in chronic disease self-care.

Patients and methods: In-depth, qualitative interviews were conducted in Spanish and English with 25 older adults with various chronic illnesses. Topics included knowledge and understanding of chronic conditions, medications, and disease self-management skills. Qualitative data were coded by searching text and conducting cross-case analysis. An inductive analysis was then employed to allow for the patterns and themes to emerge.

Results: Emerged themes included 1) social support, 2) coping strategies, 3) spirituality, 4) chronic disease health literacy, 5) anger, and 6) depression. While participants had a general overall knowledge of chronic illness, they had deficits in knowledge regarding their own illnesses and medications.

Conclusion: Chronic illness self-management is a complex and dynamic behavioral process. This study identified themes that leverage patient motivation to engage in self-care in a personalized manner. This information will guide the development of an intervention to promote health literacy and optimal disease self-management.

Keywords: health disparities, older adults, resilience, computer interventions, comorbidity, multimorbidity

\section{Introduction}

Health literacy is a critically important skill that helps people become active participants in their health care. The 2003 National Assessment of Adult Literacy showed that $>75$ million Americans had only basic health literacy skills, indicating that one in four Americans have problems understanding information about health care. ${ }^{1}$ Racial and ethnic minorities have even lower levels of health literacy. Twenty-four percent of Blacks (9.5 million persons) and $41 \%$ of Hispanics (21 million persons) have below basic levels of health literacy. Members of minorities have lower levels of health literacy, and compelling evidence links race and ethnicity to disparities in health via health literacy. ${ }^{2-8}$ Moreover, members of minority groups and older adults are also more frequently affected by chronic diseases such as cancer, high blood pressure, heart attack, diabetes, asthma, hepatitis, HIV infection, mental health disorders, and many others. ${ }^{9-13}$ Health literacy may be particularly important for management of 
these conditions since they often require adherence to rather complex treatment regimens, lifestyle changes, and regular medical care.

\section{Chronic disease self-management (CDSM)}

The twin burdens of chronic disease and low levels of health literacy thus fall disproportionately on those most in need - members of minorities and older adults, all of whom may experience one or more chronic conditions while not having the health literacy skills needed to cope. Interventions to improve health literacy are thus clearly needed. CDSM is a logical target for a health literacy intervention. In an approach that cuts across specific diseases, CDSM targets problems and skills needed to cope with issues such as fatigue, pain, stress, depression, sleep disturbance, and treatment adherence. While health conditions may require specific management skills, common issues such as fatigue, depression, stress, sleep disturbance, and treatment adherence cut across illnesses. ${ }^{14-17}$

\section{Importance of CDSM}

Non-adherence is associated with $30 \%-50 \%$ of treatment failures and as many as 125,000 deaths annually. For example, non-adherence to statins increases the risk of mortality $(\sim 12 \%-25 \%)$, non-adherence to cardioprotective medications increases the risk of cardiovascular hospitalizations $(10 \%-40 \%)$ and mortality $(50 \%-80 \%)$, and poor adherence to heart failure medications increases cardiovascular-related emergency department visits. ${ }^{18,19}$ Therefore, treatment adherence is a critical component of optimal disease management; however, only one-half of patients are estimated to be adherent to medications..$^{20}$ Adherence to treatment regimens can be complicated by many barriers, including cost and side effects of medications, the challenge of managing multiple prescriptions (polypharmacy), patients' understanding of their condition, forgetfulness, cultural and belief systems, emotional disturbances, and a reduced sense of urgency due to asymptomatic conditions. Positive clinical outcomes are more likely when patients are active participants in their care; therefore, strategies are needed that are useful in promoting self-care with longevity that will result in more effective self-management of chronic disease.

\section{Racial and ethnic older minority populations}

In the United States, Hispanics and African Americans bear a disproportionate burden of certain chronic diseases, including high blood pressure, diabetes, and cardiovascular disease; yet, few studies have investigated medication adherence among Blacks and Hispanics with multiple chronic conditions. Across all ages and even more notably by age 50 years, African Americans are living with higher rates of chronic diseases. ${ }^{21}$ Hispanics who suffer from chronic illnesses, which are associated with poorer day-to-day functioning, are at an increased risk of mortality. ${ }^{22,23}$ About $14 \%$ of Hispanics had two or more concurrent chronic diseases in 2010, up from $11.7 \%$ in 2000, while $2.7 \%$ of Hispanics had four or more chronic conditions. ${ }^{22}$ Despite greater disease burden, while several studies have investigated HIV treatment adherence among older Hispanics, ${ }^{24,25}$ very few have looked at medication adherence among Blacks and Hispanics with multiple chronic conditions. This is disconcerting since these groups in general 1) are disproportionately affected by chronic conditions, 2) have barriers related to understanding their medications and how to take them, and 3) have greater chronic illness-related mortality and morbidity than nonHispanic Whites. Poor adherence may be related to issues such as low health literacy, language, and acculturation, all of which are barriers to treatment. ${ }^{25-29}$

Racial/ethnic minorities are less likely than non-Hispanic Whites to be reached by mainstream health education, promotion, and disease prevention messages, which tend to reach middle-class, well-insured, English-speaking people. ${ }^{22,30}$ It is imperative that barriers to health care access are understood if the health needs of all groups with chronic illness are to be met. Our study proposes to gain a better understanding of patients from diverse populations' beliefs, attitudes, motivations, and behaviors regarding chronic disease and its management in order to develop an effective intervention that is acceptable and tailored to their specific needs.

\section{Materials and methods}

Qualitative methodologies are particularly important for the development of conceptual frameworks that focus on the individual, developmental, and sociocultural contexts in which behavior occurs ${ }^{31}$ to guide intervention development. This approach also helps us understand some of the cultural issues within a group sharing a similar, potentially life-altering experience. ${ }^{32}$

\section{Aim}

The purpose of this study was to gain a greater understanding of patients' perspectives on living with chronic illness, specifically related to the barriers to disease self-management and subsequently any adherence strategies they adopt. To 
answer the research questions below, a qualitative study using a thematic analytic approach was warranted.

\section{Research questions}

The research questions associated with this study are 1) What are persons with chronic illness' knowledge about and perspectives on living with their condition? 2) What do persons with chronic illness describe as the barriers and facilitators for optimal disease self-management? 3) Which commonalities and variations in disease self-management exist among patients with chronic illness? and 4) How do experiences of having to take medications for chronic illness impact persons' everyday lives? Due to the nature of qualitative inquiry, which is inductive and aims to understand culture, process, meanings, events, and experiences within particular situations, the findings are bound to particular sociocultural contexts and are not generalizable to particular groups and/ or a population. While qualitative research does not aim to test and/or prove the researchers' hypothesis, propositions can be made and researchers can confirm the propositions. ${ }^{33}$ For this study, the propositions were that older persons with chronic illness lack sufficient knowledge about their condition and have barriers and facilitators for optimal disease self-management; commonalities and variations in disease self-management exist among older persons with chronic illness; and having to take medications for chronic illness impacts everyday life.

\section{Qualitative approach}

Thematic analysis was used to identify, analyze, and report patterns (themes) within the data. This helped analyze the qualitative data and to systematically gain knowledge and understanding about the participant, ie, a person living with chronic illness. While several overarching issues regarding CDSM in patients with chronic illnesses have been identified (eg, managing pain, depression, stress, or treatment adherence), a non-tailored, one-size-fits-all disease management intervention is unlikely to be the most effective approach. This is particularly true for those from minority and socioeconomically disadvantaged communities, since relevant factors may be related not only to illness, problems, and treatment but to sociocultural factors as well.

While quantitative findings on CDSM are instructive, they do not provide an empirical understanding of the nature or essence of the lived experience per se. Given that the ability of patients to manage disease-related problems is contingent on a clear understanding of the experiences of why and how they do or are not able to adequately cope, this gap in our clinical knowledge is a significant problem and warrants further study. A qualitative approach involves a search for the meaning of the experience for these individuals and thus provides a foundation from which to build an essential understanding of what it is like to be a person coping with chronic illness.

This approach involved a descriptive method utilizing a thematic analysis by analyzing the descriptions given by participants and dividing them into meaningful statements, generating themes that guide the construction of the phenomenon being studied. This approach is best suited because there are important gaps in our knowledge about persons with chronic illness, their health literacy, and their CDSM skill. The aim of this study is to make clear and understand the most essential meaning of managing one - and oftentimes multiple - chronic illnesses from the perspective of those directly involved in it. ${ }^{34}$

A thematic analysis approach was used to gain a greater understanding of patients' health literacy and perspectives on living with chronic illness specifically related to barriers to disease self-management and subsequently any adherence strategies they adopt.

Qualitative methodologies are particularly important for the development of conceptual frameworks that focus on the individual, developmental, and sociocultural contexts in which behavior occurs. ${ }^{31} \mathrm{~A}$ better understanding of these can serve as an essential guide to intervention development. This approach also helps us understand some of the cultural issues within a group sharing a similar, potentially life-altering experience. ${ }^{32}$

Participants in this study were asked to define and describe study-related constructs using their own words and conceptualizations as they pertain to living with chronic illness and then were guided through in-depth explorations of relevant influences. Participants were encouraged to expand on details of individual stories and collective narratives when discussing their diagnoses and its ensuing issues and challenges. Using this approach allowed for less restrictive and richer responses from participants. ${ }^{32}$ This goes to say that any intervention should be responsive to the patients' holistic and global situation and not merely to the biomedical and technical aspects of a patient's body. ${ }^{34}$ The lived experience of disease self-management for chronic conditions is a complex, dynamic, and multifaceted phenomenon that is often overlooked by the prevailing biomedical model. ${ }^{35}$

\section{Data generation and collection}

Data were collected from participants from the target population to investigate factors directly related to their beliefs 
and attitudes regarding their illness that could better help us understand their needs in order to support self-management of their disease(s). Semi-structured in-depth interviews were conducted with persons with chronic illness. The overall goal was to identify core conceptual components and themes to guide the development of an intervention to improve disease self-management in this group to be developed and later tested.

\section{In-depth interviews}

Twenty-five persons with chronic illness in South Florida met the following criteria: 1) having at least one chronic condition (eg, diabetes, hypertension, hypercholesterolemia, congestive heart failure); 2) able to provide informed consent; and 3) English or Spanish speaking. Patients with any psychiatric or cognitive disorder impairing cognition or the inability to provide informed consent were excluded. This study was conducted under a protocol approved by the Institutional Review Board of Nova Southeastern University (0226102Exp). All participants provided written informed consent.

Although a goal of qualitative research is to reach saturation in eliciting themes during interviews, it is often difficult to estimate sample sizes for this research strategy prior to data collection. However, it has been suggested that 5-25 participants are adequate for this type of qualitative scientific inquiry. ${ }^{36-38}$ In this study, we continued interviews until we found that we had thoroughly explored all emergent themes raised by our participants.

\section{Recruitment}

Participants were recruited from a list of people who had participated in some of our previous studies. Flyers describing general study information were posted in the universitybased clinic in which the researchers are employed. Interested persons were then contacted by our staff for preliminary eligibility screening and to set up an appointment for the one-time interview.

\section{Qualitative procedure}

A semi-structured interview guide (based on the literature and informal interviews with key informants, ie, health care providers, pharmacists, other providers experienced with our population of interest), which consisted of open-ended questions designed to elicit rich descriptions, was developed. Constructivist frameworks guided the creation of the semistructured interview guide.

The participant interviews were conducted in English or Spanish and digitally recorded. Interviews were then transcribed, coded, and analyzed. In this method, data were collected from multiple members of the population in order to gain a richer understanding of the phenomena of interest. This approach helped the researchers to understand the sociocultural behaviors within a group sharing a similar, potentially life-altering experience. ${ }^{32}$

Participants were asked to define and describe studyrelated constructs (eg, how they cope with managing problems such as pain, stress, or depression) using their own words and conceptualizations and then were guided through in-depth explorations of relevant influences. Participants were encouraged to expand on details of individual stories and collective narratives when discussing their illness diagnosis and its ensuing issues and challenges. Using this approach allowed for less restrictive and more culturally rich responses from participants.

Although interviews covered the same material, they were tailored to each participant's unique situation. The following broad content areas were included: 1) knowledge of chronic illness, 2) medication-taking behaviors, 3) personal decision making and motivations for disease self-management and medication adherence, 4) coping and social support, 5) benefits and barriers to self-management, 6) perceptions (self-concept) of being a person with chronic illness, 7) role of culture in disease self-management, and 8) ways they think they can improve their self-management behaviors. Since these discussions were open-ended, the order of questions may have changed somewhat, and follow-up questions for clarification may have been asked. Participants were asked to use a pseudonym during the recorded interview to protect their identities. The interviews lasted $\sim 1$ hour.

\section{Data preparation and analysis}

Individual interviews were transcribed, coded, and analyzed. An inductive analysis was used because it allows for the patterns, themes, and categories of analysis to emerge. ${ }^{39}$ Two levels of qualitative analysis were conducted. The descriptive analysis described the respondents' life situations and characteristics. The thematic analysis elaborated the structures of the basic constructs and new constructs that arose in the early analysis. Two readers reviewed transcripts of the first five interviews to identify all relevant ideas. Their notations were compared and discussed. The process was repeated for the remaining transcripts until there was agreement on the ideas and concepts. Some of the concepts were broken down into various subcomponents of the theme. The next stage of analysis was to go back to the individual interviewee level 
to look at within-person consistency with each concept. The two readers assembled and compared all the text references to a concept. It was determined to what extent respondents affirmed only single aspects or multiple aspects of a concept. This built on the earlier descriptive analysis and will allow to distinguish among respondents. This permitted the readers to ensure that they incorporated differences and similarities that might emerge among these interviewees. Descriptive node tree diagrams were created using NVivo software ${ }^{40}$ in order to assist in the interpretation of the comparative analysis findings. In this way, the readers ensured scientific rigor of the qualitative analysis by making sure the themes and contexts derived were correct in that credibility, reliability, and dependability can be demonstrated.

\section{Results}

The goal was to complete interviews with patients with chronic diseases in order to lay the groundwork for intervention content development. All participants completed the qualitative face-to-face interviews in either English or Spanish. Of the English-speaking participants, four were men and 11 were women. Ages of participants ranged from 62 to 88 years $($ mean $=77.1$ years $)$. Five participants were African American, and 10 were non-Hispanic White. Of the Spanishspeaking participants (identified as Hispanic white), two were men and eight were women. Ages of participants ranged from 57 to 77 years ( mean $=66.7$ years). Chronic illnesses reported for all participants included diabetes, hypertension, cardiovascular disease, hyperlipidemia, asthma, arthritis, anxiety, and chronic migraines.

\section{Summary of qualitative findings}

The emergent themes from the participant qualitative interviews included 1) disease knowledge acquisition and health literacy; 2) role of spirituality; 3 ) social and family support; and 4) coping strategies.

\section{Disease knowledge acquisition and health literacy}

While participants had a general overall knowledge of chronic illness (eg, diabetes means too much sugar in the blood), they had some overall deficits in knowledge regarding some of their illnesses and medications but knew more about those conditions for which they tried to gain control over. One participant who suffers from both chronic migraines and asthma reported:

[I know] more on asthma than I do on migraines. I've had them for so long, I know pretty much, but the asthma I don't know a lot about. And I actually, I don't really realize how serious asthma can be, because I really don't know that much about it [...] I think I became more knowledgeable about them [migraines] in learning how to deal with them and trying to figure out the triggers for them on my own more than anything else, which I guess everybody is different. I mean, I could get them from M\&Ms, but the next person maybe that gets migraines doesn't have them from that, they get them from milk. I had a doctor that I used to go to, she used to get it from milk. Now I don't. I could drink a gallon of milk and it wouldn't even phase me. So I've had to learn, and I think I've developed that on my own, is learning what bothers me for myself, my migraines, and also what they do to you, to your body, to your life. It's, yeah, you know, I've studied and learned about them just looking them up and reading all about it. [White female, age 65 years]

However, most of the participants knew only the name of the medication, what it does (basically), and when to take it.

Well, I know the metformin - if your blood sugar's low and everything, you can take one and that'll help bring it back up, you know, mostly. But I take that in the mornings and at night. [African American female, age 81 years]

When asked how well she understood how her asthma worked in her body, one participant commented:

About 50 percent. I mean, I know that I should take my inhaler, my ADVAIR, every day and then use the rescue inhaler as needed. [White female, age 74 years]

When asked where they typically found health and medical information, participants reported they got most of their information from their doctors, pamphlets and other reading materials from the physicians' office, or Internet sources. While the majority utilized generic search engines such as Google, there were a few participants who accessed reputable and more specific Web sites such as WebMD.

WebMD I love. I read that one a lot. I trust that one more is what it is. More than anything, and then I go to the association itself, like the headache, for migraines, or Mayo Clinic, I like them. [White female, age 65 years]

I, you know, you go to the doctors, they have pamphlets or something and I just read a little about it [...] well, I think I kinda understand it. I'm not a pro on it, I wouldn't say, but I do understand it if such-and-such a thing is and such-andsuch a thing, such-and-such a thing would happen, that type thing. [African American female, age 81 years] 
Participants were asked how well they understood the material they read about their medications and the possible interactions with other medications they might be taking. Overall, they limited themselves to reading only about the side effects from the paperwork accompanying their prescription medications. When asked they think they need to know more information about their chronic illness, the younger participants thought that perhaps they did, but the older participants were content to get the information from their physicians.

Since I had the diabetes for a while now, I'm pretty much up on - pretty much - the up and downs about it. And, with the heart, I'm watching that too, with my heart doctor. I have a very good heart doctor. And he keeps me up to date on everything. Like next month I go to him again. [African American female, age 83 years]

Others relied on community services to provide information.

I go to this center in [name of town], the senior center, and they have a lot of people that come to that, and they take us through a lot of these different illnesses, and we get a lot of information through them. [African American female, age 84 years]

\section{Spirituality}

Many participants reported instances in which their faith played a role in coping with chronic illness. One participant discussed his reaction to finding out about his heart condition.

Well, I took it in stride in a way. I mean, I needed the surgery to put the stents in and somehow it didn't bother me. I'm pretty religious and I have a feeling that - I have a strong sense of God and I think God looks over me. [White male, age 75 years]

For some, faith in God was solidified prior to getting sick and has since carried them through the battles with chronic illness.

I loves the lord Jesus Christ. He's been carrying me for 34 years, that and plus 62 in my life. Wasn't for him, I wouldn't be sitting here today, out of what I took myself through, Getting off of drugs, getting hit by cars, getting left for dead, you know? But only through the lord Jesus Christ brought me through. He made me see, "You got to stop. Is you're going to be on the right side or are you going to be on the left side?" He said, "You cannot straddle." He said, "You've got to be on my side. You can't serve me and the devil too." So that devil, but he's powerful, because he had hooked me for 40 years. I was on drugs for 40 years, ma'am, and I mean, he had his hooks in me like so, so deep, oh boy, it took the lord Jesus Christ to get them out. [African American female, age 62 years]

One woman discussed her belief in God after a breast cancer diagnosis that led to a mastectomy.

So anyway, I went to the doctor [...] we sat and we talked [...] with all of the information that I received. Then I just thought. I said, "Listen, Alma*, you're a big girl, and these things happen." I just began talking to myself, and I'm a believer in God. I just said I'm gonna put it in his hands. Whatever happens, whatever the diagnosis, if I have to have the mastectomy or whatever has to be done, I'm just gonna go ahead and have it done [...] take your burden to the Lord and leave it there. I just really believe that God hears, and he answers prayers. [African American female, age 84 years]

\section{Support}

\section{Family/social support}

Support was reported as a critical element in dealing with chronic illness. Many of the participants discussed the importance of having some kind of social support, whether it be from family or friends.

I have a daughter that call me every day. She bugs me. She bug me every day. She live in [name of town]. She'll call me every day. I just talked to you. I say, I'm feeling fine, you know. 'You wouldn't be lying to me would you? You know what I mean?' [African American male, age 71 years]

Other participants use their religious/spiritual organization to provide support.

Well, I get a lot from the synagogue and also, I mean, we have our friends that we go out with socially. We go to movies. [White male, age 75 years]

I'm not looking for social support from friends, because I don't trust so much. But I do have one good friend that I did feel that she betrayed me once, but never mind. I try not to think of it. And otherwise it's mostly talking and phone calls. I don't open up, except to one friend, my heart to anybody, except my husband. [White female, age 73 years]

Some participants confessed it was difficult to accept support from others.

Well, it's very hard because I'm so used to doing things for myself, and if I ask you to do something one time, I'm 
not gonna ask you twice or three times. I'll do it myself. To me if you ask a person more than once, you're begging that person to do something, and that mean they don't want to do it in the first place. So I do it myself. And they'd say, oh I'll go and do it. When, tomorrow sometime, it doesn't have to be done then? I'll tell 'em right then, I'm just gonna cut you loose. That's what I say. [African American male, age 71 years]

\section{Coping strategies}

For participants, staying positive was reported to be an important factor in coping with pain and combating anxiety and depression. Many participants discussed cognitive selfmanagement strategies for coping with their illnesses. Many of these included reframing the meaning of their lives and illnesses and positive self-talk to maintain their ability to cope with multiple health problems on a daily basis. They also discussed behavioral self-management strategies, such as exercise, as a means of coping.

How do I deal with things? I usually try to ignore them [...] and I'll try to see the positive in each situation, the good thing. Maybe according to the book, it might not be good, but who cares about the book? I know I can't change things $[\ldots]$ we can't change it, so why don't just see the positive of it? [...] can't change the past. That's what I'm saying. Whatever happened, happened. Can't change it. And if things are okay now, to be happy in the moment. And we are not here forever. That's what I tell myself, too. We're not here forever, so just enjoy the moment. [White female, age 73 years]

Well, in my cases, I say to myself, for instance, this thing in my back is bothering me now. Look how much worse the rest of the world is. Look how much worse everybody else - I watched a friend of mine die of cancer [...] and I had never seen anything like that up close [...] I never saw anybody go like that, and what a terrible way to go. Wouldn't I rather walk around the way I am than change places with someone like that? So maybe, are you lucky, are you not lucky? I don't know. But I think I'm comparatively lucky. [White female, age 86 years]

Whatever it is, it's up to you to have your mind help you to overcome it. That doesn't mean that it's gonna cure you. And it may. But at least you can live with it, which is what I did. And somehow or other, it seems to mean something. I said, “I'm not being boastful in saying I did and so can you. What I'm saying is it works. It works because your mind controls your body." And I feel so strongly about that. [White female, age 89 years]

Others used more external strategies:

One of the happiest place I'm in is working out, going to the club. So once I'm doing exercise, the machine, the spinning, the classes, the dancing, I feel ageless. I feel like I can do better than the 29 year olds. So I'm fine. I'm happy. That keeps me happy. Working out. And volunteering. I do a lot of volunteering. [White female, age 73 years]

Some reactions to the stress of chronic illness and subsequent pain included anger and lashing out at others. When asked how she handled anger, one participant responded:

If I'm around anybody, I take it out on them. But if I'm alone, I curse him out, I cry [...]. [African American female, age 62 years]

Also reported was the use of alcohol and prescription medications to help cope their chronic illness.

One time I slept for a whole week [...] when I first got sick, I used to sleep all the time. I used to go to the doctor and get Xanax. I used to get Valium. Anything that would make me sleep, or if not that, I would get super drunk, super, super drunk, take pills, anything just to sleep, because I didn't want to see it. I didn't want to feel. All I wanted to do was sleep, and that's how I am now. When I have pains and I can't get rid of them, I'm aching, the medication is not working, and since I stopped drugging, I stopped taking any kind of pills, pain pills, I don't take nothing now but Ibuprofen 800 s. When they don't work, I just go to bed. And you know, when I wake up I feel better. [African American female, age 62 years]

\section{Anger}

Many participants reported feelings of anger due to variety of issues regarding problems due to their illness. For one participant who suffers chronic migraines, her frustration and anger stem from friends, family, and physicians not acknowledging the debilitating nature of the conditions.

It's not just a headache, and that's where a lot of neurologists I went to, they talk to you like, "Oh, it's just a headache." No, it's not. It controls you. You can't cope with anything. You can't work, you can't function. That's something I don't think a lot of people realize. "Oh, it's just a headache. You'll be all right." No it's not. It's more than that, and it affects your personality, it affects a lot of things that people don't 
realize. [...] Because I would get angry at people who would say that, and I was moody when I'd have them [... I I couldn't control that. I felt like I couldn't. It was my body. It was hurting so bad, yes, I am moody, but I can't help that [...]. I get frustrated or angry even if I don't have a migraine, let's say I go to my friend's or something like that. "Well why do you get so many? Why can't they do something about it?" I get angry [...] so I'd rather avoid being with them. [White female, age 65 years]

Other participants stressed that they get angry because they find they cannot do the things they used to do before.

I do get angry, there's no question about that. I get angry because of the things that I used to do, I can't do anymore. I went [to the gym], and I could not keep up with the class. So even the instructor said, "Well, just do what you can." And I couldn't. First of all, when you're doing something in front of a bunch of people and you feel like a clod, so I gave that up. I didn't - you know, usually if I stand in front of a bunch of people, they're laughing at me for other reasons. And I just couldn't take that. [White male, age 80 years]

\section{Depression}

For some participants, depression was linked to physical pain due to their chronic illness; they felt if they did not have pain, they would not be depressed.

Sometimes when the pain is too strong I want to cry and like I get depressed, like you get depressed but that's for a moment. I encourage myself and that will go away. [Hispanic female, age 77 years]

Others reported feeling depressed but utilized different strategies to cope with it.

I'll just think of other people and I'll say, "You know, I could have this, I could have cancer, it could be worse. I'll get over it. I'll be okay," and I don't want to fall into a depression or anything, so that's what I do. I'll tell myself, "You know what? This isn't as bad as what it could be. It could be a lot worse," and that's how I talk myself out of it. [...] Years ago I used to get very depressed with them [illnesses], because it was a constant thing. I had no life. I never had a clear head. I always had this dull headache in the back of my head, always brewing. So it made me crabby and cranky and I just couldn't function, whereas now I just look at other people and think, "Oh wow, it could be worse. This is okay. I can handle it." I never looked at it like that. I just more or less felt sorry for me, "This is what I have," and I would get real depressed. I'd just stay in my room, wouldn't talk to nobody, go nowhere [...] It would be months where I just wouldn't even go out, wouldn't talk to anybody. [White female, age 65 years]

For some, the depression can be debilitating.

I have terrible depression. The kind that you don't wanna get out of bed in the morning. And then you force yourself to get out of bed, and then you say, "Well what am I gonna do today?" Because I used to go to volunteer things. I used to do all kinds of things. I just wanna stay home and read a book. And many days, that's what I do. But I go out if I need to or if I want to or whatever. I still drive. I've got a little car. [White female, age 87 years]

Some participants reported their depression was due to not being able to function as they had in the past and being told they have to make adjustments in life.

Well, the backache is uncomfortable to sleep, sometimes I can't be sitting for long periods and I have to stand up and stretch the back, I can't bend, I can't lift - I mean, it's I don't cook, and that's part of depression because I want to do things and I can't do it, I can't work. The psychiatrist's assistant told me, "Part of your life has been taken away, the way you are." Exactly, I don't have - I could be the whole day in bed, and that's because of the depression I have. [Hispanic female, age 57 years]

\section{Discussion}

The aim of this research was to obtain a deeper understanding of older adults' perspectives on the challenges of living with chronic illness as they pertain to health literacy and disease self-management strategies they utilize. Several themes emerged from the interviews: spirituality, social support, coping, anger, and depression in this group of older adults with chronic illness. These findings support the literature evidence that certain psychological and sociocultural variables might influence managing chronic illness including medication adherence, but the details provided by participant narratives provided a deeper, richer understanding of the underpinnings and possible interrelatedness of these factors.

Regarding chronic illness knowledge and perspectives on living with their condition, one of the study's research questions, participants commented on how little they actually knew and understood about their diseases, a finding supported by Shaw et al, ${ }^{41}$ although they understood the importance of taking medications, the names of their medications, and how 
to take them. This finding is in line with our proposition that the participants may lack sufficient knowledge about their condition. Of note is their reported limited use of the Internet to find health information, and when they do utilize online searches, the searches are not via targeted Web sites (eg, WebMD) that provide quality, reliable, and more accurate information than a Web site whose mission is to sell a product. This is problematic in that the medical information available on the Internet can create harm by being difficult to interpret and thus creating the potential of overuse or misuse of treatment or medication. Moreover, there are insufficient tools available that assist patients in finding relevant information given the vast amounts of health information on the Internet. Health and medical information needs to be easy to locate, relevant to the patient and their illness, and understandable for patients with low levels of health literacy. This finding also aligns with our proposition that there are barriers for optimal disease self-management.

There is little published work regarding the role of spirituality and religious faith in disease self-management among persons with chronic illness. Nonetheless, there is literature to support the idea that a strong spiritual base has an influence on resilience and coping skills among older persons ${ }^{42}$ and Hispanics with chronic illness. ${ }^{43}$ For some, particularly African Americans, the roles of spirituality and social support are intertwined, whereby church activities provide not only spiritual fulfillment but social support as well. ${ }^{44,45}$ Spirituality may be a commonality in disease self-management among older persons with chronic illness, supporting the proposition that similarities may be present in this group. Therefore, it would be important when, in developing disease self-management interventions, to take into account the function of the church and spiritual values for patients. More research is needed in how we can leverage these components for better health outcomes.

Aside from support provided by the church, support from family members and friends was reported as crucial for aiding self-management of chronic illness. ${ }^{46}$ The majority of the participants concurred that social support was paramount, whether it comes from the church, a close friend, an acquaintance, or a family member and even if it was just a phone call. The protective effects of high-quality social support can enhance emotional and physical well-being and increases resilience to stress. ${ }^{47}$ Yet, participants remarked that it was not always easy to ask for or find support in times of emotional and/or physical need. For some participants, it was difficult to accept losing some independence and to adapt to the change in social role (eg, transitioning from an active member in society to not being part of the work force due to chronic illness). Creating access to a supportive social environment would be an essential component in any intervention for persons with chronic illness, one that would motivate participants to reach out and access people who can be available to them when needed or teach them how to create new social networks. Also, participant's perceptions about support may need to be taken into account, such as understanding when they might need it and who they feel can provide it and if they will be satisfied with the interaction.

Teaching communication skills regarding interpersonal interactions will help participants to nurture supportive relationships. Reports of feeling depressed were not surprising given experiences of depression is common among persons with chronic illness. ${ }^{24,25,48,49}$ In this sample, much of the reported depression was due to pain caused by their illnesses and inability to function as they had previous to becoming ill. Of importance to note is that depression can interfere with a person's ability to self-manage disease, particularly regarding motivation to adhere to a medication regimen. ${ }^{50}$ Feelings of anger and frustration were reported among several participants due to having to face problems stemming from their illness and, as mentioned earlier, not being able to do things they used to do, such as exercise. Addressing how mood affects self-management for a variety of health issues provides leverage for developing intervention approaches to improve medication adherence and enhance motivation for disease self-management overall.

At the core of wellness is the ability to cope and adapt to new circumstances. For this reason, it is imperative that persons with chronic illness learn to develop strategies to help them cope with the challenges accompanying illness, much of which involves maintaining a positive attitude and at times making the adaptive process less emotionally overwhelming. With chronic illness comes a loss of a valued level of functioning, such as the ability to engage in activities such as driving, dancing, or exercising.

There seemed to be a relatively high level of acceptance and adaptation regarding their illnesses in this sample of older adults, many of whom suffered from multiple chronic conditions. Part of disease management is adapting to circumstances beyond one's control. Illness acceptance may be instrumental in older adults' adaptation to health limitations. ${ }^{51}$ As revealed by the study participants, patients develop their own coping strategies, some maladaptive (substance use, lashing out in anger). Learning adaptive coping skills can enhance CDSM skills by helping the person change 
expectations regarding their physical abilities, ie, to work within the limit of those abilities. These skills also include managing anger and intermittent depression, help approach problems actively, enhance help-seeking behaviors, and build social support networks. For older adults, support provided by their environment is also instrumental. ${ }^{52}$

\section{Limitations}

Several limitations associated with this study should be considered. Findings from this small sample cannot be extended or generalized to wider populations of noncommunity-dwelling adults with chronic illness, ie, those who receive care in hospitals or at home, or to persons living in more rural settings. The generalizability of this study is for the sole purpose of developing an intervention to be tested in a larger study. Replicability is very problematic. It is difficult to make systematic comparisons as participants may give widely differing responses that are highly subjective.

\section{Conclusion}

The focus of this study was to explore patients' perspectives on living with chronic illness including their health literacy and health behavior strategies. Several salient themes related to living with chronic illness emerged from the data collected from the interviews. Many commonalities existed among participants regarding barriers and facilitators for optimal disease self-management, with some sociocultural variations, particularly regarding the role of culture and spirituality.

Of note throughout the thematic analysis of this study was the level of personal and emotional resilience participants demonstrated when it came to CDSM in the face of physical pain, isolation, depression, and lack of support. While more difficult to express or even detect, challenges associated with emotional distress can cause and/or exacerbate physical manifestations of illness. ${ }^{53}$ The participants disclosed their ways of dealing with their stressors that may or may not be related to personal resilience. An association has been shown to exist between resilience and quality of life and health promotional behavior. ${ }^{54}$ It is likely that more research is required to deepen the understanding of the role of resilience influences on coping and CDSM in older adults.

Increasing knowledge and understanding of chronic illnesses combined with enhancing skills for CDSM may be paramount for any future health interventions with this population. ${ }^{55}$ Moreover, tailoring interventions to provide personalized information specific to the user, ie, addressing their unique deficits and their strengths, can help improve CDSM competency in patients.

\section{Acknowledgments}

This study was supported by a grant from the National Institutes of Health/Office of Health and Human Services (R56 HL096578 05A1).

\section{Disclosure}

The authors report no conflicts of interest in this work.

\section{References}

1. Cutilli CC, Bennett IM. Understanding the health literacy of America results of the national assessment of adult literacy. Orthop Nurs. 2009;28(1):27-34.

2. Berkman ND, Sheridan SL, Donahue KE, et al. Health literacy interventions and outcomes: an updated systematic review. Evid Rep Technol Assess (Full Rep). 2011;199:1-941.

3. Osborn CY, Cavanaugh K, Wallston KA, et al. Health literacy explains racial disparities in diabetes medication adherence. J Health Commun. 2011;16(suppl 3):268-278.

4. Osborn CY, Cavanaugh K, Wallston KA, White RO, Rothman RL. Diabetes numeracy. Diabetes Care. 2009;32(9):1614-1619.

5. Osborn CY, Paasche-Orlow MK, Bailey SC, Wolf MS. The mechanisms linking health literacy to behavior and health status. Am J Health Behav. 2011;35(1):118-128.

6. Pignone M, DeWalt DA, Sheridan S, Berkman N, Lohr KN. Interventions to improve health outcomes for patients with low literacy. $J$ Gen Intern Med. 2005;20(2):185-192.

7. Waldrop-Valverde D, Jones DL, Gould F, Kumar M, Ownby RL. Neurocognition, health-related reading literacy, and numeracy in medication management for HIV infection. AIDS Patient Care STDS. 2010;24(8):477-484.

8. Waldrop-Valverde D, Osborn CY, Rodriguez A, Rothman RL, Kumar M, Jones DL. Numeracy skills explain racial differences in HIV medication management. AIDS Behav. 2010;14(4):799-806.

9. Angel JL, Angel RJ. Minority group status and healthful aging: social structure still matters. Am J Public Health. 2006;96(7):1152-1159.

10. Cargill VA, Stone VE. HIV/AIDS: a minority health issue. Med Clin North Am. 2005;89(4):895-912.

11. Liu L, Nunez AE, An Y, et al. Burden of cardiovascular disease among multi-racial and ethnic populations in the United States: an update from the National Health Interview Surveys. Front Cardiovasc Med. 2014;1:8.

12. Primm AB, Vasquez MJ, Mays RA, et al. The role of public health in addressing racial and ethnic disparities in mental health and mental illness. Prev Chronic Dis. 2010;7(1):A20.

13. Stone VE. Optimizing the care of minority patients with HIV/AIDS. Clin Infect Dis. 2004;38(3):400-404.

14. Jaglal SB, Guilcher SJ, Hawker G, et al. Impact of a chronic disease self-management program on health care utilization in rural communities: a retrospective cohort study using linked administrative data. $B M C$ Health Serv Res. 2014;14(1):198.

15. Newman S, Steed L, Mulligan K. Self-management interventions for chronic illness. Lancet. 2004;364(9444):1523-1537.

16. Ory MG, Ahn S, Jiang L, et al. Successes of a national study of the chronic disease self-management program: meeting the triple aim of health care reform. Med Care. 2013;51(11):992-998.

17. Page TF, Palmer RC. Intermediate outcomes of a chronic disease self-management program for Spanish-speaking older adults in South Florida, 2008-2010. Prev Chronic Dis. 2013;10:130016.

18. George J, Shalansky SJ. Predictors of refill non-adherence in patients with heart failure. Br J Clin Pharmacol. 2007;63(4):488-493. 
19. Ho PM, Bryson CL, Rumsfeld JS. Medication adherence. Circulation. 2009;119(23):3028-3035.

20. Lavsa SM, Holzworth A, Ansani NT. Selection of a validated scale for measuring medication adherence. JAm Pharm Assoc. 2011;51(1):90-94.

21. Collins KS, Tenney K, Hughes DL. Quality of Health Care for African Americans: Findings from the Commonwealth Fund 2001 Health Care Quality Survey. New York, NY: Commonwealth Fund; 2002.

22. National Council of La Raza. An Inside Look at Chronic Disease and Health Care among Hispanics in the United States; 2014. Available at: www.lchc.org/wp-content/uploads/Chronic_Disease_Report_2014.pdf. Accessed February 1, 2017.

23. Centers for Disease Control and Prevention. Behavioral Risk Factor Surveillance System Survey Data. Atlanta, GA: US Department of Health and Human Services, Centers for Disease Control and Prevention; 2014.

24. Jacobs RJ, Caballero J, Ownby RL, Acevedo A, Kane MN. Motivational factors related to medication adherence in Spanish-dominant Hispanics living with HIV. J HIV AIDS Soc Serv. 2015;14(3):337-358.

25. Jacobs RJ, Caballero J, Ownby RL, Kane MN. Development of a culturally appropriate computer-delivered tailored Internet-based health literacy intervention for Spanish-dominant Hispanics living with HIV. BMC Med Inform Decis Mak. 2014;14:103.

26. Alcaide ML, Castro JG. Health literacy and treatment adherence in Hispanic HIV-infected patients. Fla Public Health Rev. 2009;6:62-67.

27. Jacobs RJ, Lou JQ, Ownby RL, Caballero J. A systematic review of eHealth interventions to improve health literacy. Health Informatics $J$. 2016;22(2):81-98.

28. Singleton K, Krause E. Understanding cultural and linguistic barriers to health literacy. Online J Issues Nurs. 2009;14(3). Available at: http:// www.nursingworld.org/MainMenuCategories/ANAMarketplace/ANAPeriodicals/OJIN/TableofContents/Vol142009/No3Sept09/Culturaland-Linguistic-Barriers-.html. Accessed February 1, 2017.

29. van Servellen G, Lombardi E. Supportive relationships and medication adherence in HIV-infected, low-income Latinos. West $J$ Nurs Res. 2005;27(8):1023-1039.

30. Jesus M, Xiao C. Predicting Internet use as a source of health information: a "language divide" among the Hispanic population in the United States. Policy Internet. 2012;4(2):1-11.

31. Lambert TW, Guyn L, Lane SE. Development of local knowledge of environmental contamination in Sydney, Nova Scotia: environmental health practice from an environmental justice perspective. Sci Total Environ. 2006;368(2):471-484.

32. Creswell JW. Research Design: Qualitative, Quantitative, and Mixed Methods Approaches. Thousand Oaks, CA: SAGE Publications; 2013.

33. Ritchie J, Lewis J, Nicholls CM, Ormston R. Qualitative Research Practice: A Guide for Social Science Students and Researchers. SAGE Publications; Thousand Oaks, CA: 2013.

34. Giorgi A. The theory, practice, and evaluation of the phenomenological method as a qualitative research procedure. J Phenomenol Psychol. 1997;28(2):235-260.

35. Bayliss EA, Bonds DE, Boyd CM, et al. Understanding the context of health for persons with multiple chronic conditions: moving from what is the matter to what matters. Ann Fam Med. 2014;12(3):260-269.

36. Flick U. An Introduction to Qualitative Research. Thousand Oaks, CA: SAGE Publications; 2009.
37. Guest G, Bunce A, Johnson L. How many interviews are enough? An experiment with data saturation and variability. Field methods. 2006;18(1):59-82.

38. Mason M. Sample size and saturation in $\mathrm{PhD}$ studies using qualitative interviews. Paper presented at: Forum Qualitative Sozialforschung/Forum: Qualitative Social Research; 2010. Available at: http:// www.qualitative-research.net/index.php/fqs/article/view/1428/3027. Accessed February 1, 2017.

39. Lincoln YS, Guba EG. Naturalistic Inquiry. Vol. 75. Thousand Oaks, CA: SAGE Publications; 1985.

40. Ltd. QIP. NVivo qualitative data analysis Software Version 10; 2012.

41. Shaw SJ, Armin J, Torres CH, Orzech KM, Vivian J. Chronic disease self-management and health literacy in four ethnic groups. $J$ Health Commun. 2012;17(suppl 3):67-81.

42. da Rocha AL, Ciosak SI. Chronic disease in the elderly: spirituality and coping. Rev Esc Enferm USP. 2014;48:87-93.

43. Hunter-Hernández M, Costas-Muñíz R, Gany F. Missed opportunity: spirituality as a bridge to resilience in Latinos with cancer. $J$ Relig Health. 2015;54(6):2367-2375.

44. Becker G, Newsom E. Resilience in the face of serious illness among chronically ill African Americans in later life. J Gerontol B Psychol Sci Soc Sci. 2005;60(4):S214-S223.

45. Cummings SM, Neff JA, Husaini BA. Functional impairment as a predictor of depressive symptomatology: the role of race, religiosity, and social support. Health Soc Work. 2003;28(1):23-32.

46. Gallant MP, Spitze G, Grove JG. Chronic illness self-care and the family lives of older adults: a synthetic review across four ethnic groups. J Cross Cult Gerontol. 2010;25(1):21-43.

47. Ozbay F, Fitterling H, Charney D, Southwick S. Social support and resilience to stress across the life span: a neurobiologic framework. Curr Psychiatry Rep. 2008;10(4):304-310.

48. DeJean D, Giacomini M, Vanstone M, Brundisini F. Patient experiences of depression and anxiety with chronic disease: a systematic review and qualitative meta-synthesis. Ont Health Technol Assess Ser. 2013;13(16):1-33.

49. Katon WJ. Epidemiology and treatment of depression in patients with chronic medical illness. Dialogues Clin Neurosci. 2011;13(1):7-23.

50. Ownby RL, Jacobs RJ, Waldrop-Valverde D, Gould F. Depression care and prevalence in HIV-positive individuals. Neurobehav HIV Med. 2010;2:73-83.

51. Cybulski M, Cybulski L, Krajewska-Kulak E, Cwalina U. Illness acceptance, pain perception and expectations for physicians of the elderly in Poland. BMC Geriatr. 2017;17(1):46.

52. Cybulski M, Krajewska-Kulak E, Jamiolkowski J. Preferred health behaviors and quality of life of the elderly people in Poland. Clin Interv Aging. 2015;10:1555.

53. Liddy C, Blazkho V, Mill K. Challenges of self-management when living with multiple chronic conditions: systematic review of the qualitative literature. Can Fam Physician. 2014;60(12):1123-1133.

54. Cal SF, Sá LRd, Glustak ME, Santiago MB. Resilience in chronic diseases: a systematic review. Cogent Psychol. 2015;2(1):1024928.

55. Jacobs R, Kane M. Teaching disease self-management skills to older adults with multimorbid chronic conditions using mobile technology health education interventions. Paper presented at: 9th annual International Conference of Education, Research and Innovation; Seville, Spain, 2016.
Journal of Multidisciplinary Healthcare

\section{Publish your work in this journal}

The Journal of Multidisciplinary Healthcare is an international, peerreviewed open-access journal that aims to represent and publish research in healthcare areas delivered by practitioners of different disciplines. This includes studies and reviews conducted by multidisciplinary teams as well as research which evaluates the results or conduct of such teams or health
Dovepress

care processes in general. The journal covers a very wide range of areas and welcomes submissions from practitioners at all levels, from all over the world. The manuscript management system is completely online and includes a very quick and fair peer-review system. Visit http://www.dovepress.com/ testimonials.php to read real quotes from published authors. 